\title{
Activated kaolin's potential adsorbents for the removal of Derma Blue R67 acid dye: kinetic and thermodynamic studies
}

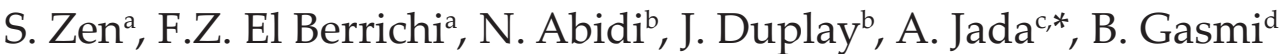 \\ aLaboratoire de chimie appliquée, Université de 08 Mai45, BP 401, Guelma, Algeria, emails: soumia.zene@yahoo.fr (S. Zen), \\ zora172001@yahoo.fr (F.Z. El Berrichi) \\ ${ }^{b}$ EOST, Laboratoire d'Hydrologie et de Géochimie de Strasbourg, 1 rue Blessig 67084 Strasbourg cedex, France, \\ emails: jduplay@unistra.fr (N. Abidi),nejibabidi@gmail.com (J. Duplay) \\ 'Institut de Sciences Des Matériaux De Mulhouse (IS2M), 15 rue Jean Starcky, BP 2488, 68057 Mulhouse cedex, France, \\ email: amane.jada@uha.fr \\ 'Laboratoire de physique des couches minces et applications, Université Mohamed Khider, Biskra, Algeria, \\ email: brahimgasmi91@yahoo.fr
}

Received 9 November 2017; Accepted 1 February 2018

\section{A B S T R A C T}

In the present work, two Algerian clay samples, Djebel Debagh (DD3) and Tamazert (KT2), were used as adsorbents for the removal from the water of Derma Blue R67, which is an acid dye commonly used in the tanning industry. The two clay samples used were first treated by acid in order to enhance their retention capacities, and then characterized using X-ray diffraction, scanning electron microscopy, surface area measurements (Brunauer, Emmett et Teller method (BET)), surface charge (points of zero net proton charge), and electrophoretic mobility (Zetaphoremeter). Further, the adsorption experiments of the acid dye from water onto the clay surface were carried out by investigating various parameters such as, the contact time, the initial dye concentration, the aqueous phase $\mathrm{pH}$, the clay amount and the temperature. The results indicate that the two adsorbents are efficient and that the anionic dye removal from water is mainly feasible at ambient temperature. Further, the comparison of the experimental adsorption data to the prediction models has shown that the Langmuir model gives the best fit, indicating the formation of a monolayer by the acid dye molecules on the clay surface. Finally, the adsorption kinetics follows a two-type process onto KT2 kaolinite, whereas onto DD3, it only follows the pseudo-second order model. From the overall data, it is concluded that the Algerian local kaolin clays are good adsorbent candidates for wastewater treatments.

Keywords: Activated kaolins; Tannery dye; Kinetics; Thermodynamics of adsorption

\section{Introduction}

Textile and tannery effluents are among the most polluting industrial wastes, and the problem of treatment and disposal of such wastes requires much attention. A certain amount of dye is lost in the manufacturing processes and remains in their effluents. Moreover, it may be released in aqueous effluents such as in the river streams which become coloured. Further, the dyes used in the tanning process or in textile are toxic to living organisms, due to their low biodegradability and persistence in the environment, and their presence in wastewater induces a risk to human health $[1,2]$. Therefore, effluents have to be treated carefully before discharge. As regulations become more stringent, complicated and multi-step treatments for the raw dye wastewater are required, and the removal of dyes is usually the key point.

\footnotetext{
* Corresponding author.
} 
For example, in Algeria, domestic and industrial raw wastewater is discharged anywhere in the environment and causes pollution, it is more and more dangerous for water resources and public health. The amounts of industrial effluent discharge estimated on the basis of a sample of 100 industrial units, show that industrial companies produce a volume of 100 to 130 million $\mathrm{m}^{3}$, with a pollution load of more than 55,000 tons of biological oxygen demand $\left(\mathrm{BOD}_{5}\right)$ in the industries textiles and tannery $(22 \%)$. The treatment capacity of existing industrial effluents represents about 20 million $\mathrm{m}^{3} /$ year, some $10 \%$ of the volume of wastewater generated. There are several methods for dye removal such as biological treatment [3-7], coagulation/flocculation [3,7,8], ozone treatment $[5,8]$, chemical oxidation and photocatalytic processes [9-11], membrane processes [5,8,12-15] and adsorption $[8,16]$. Among these methods, the most efficient one is the adsorption process, because it is simple in terms of operation and can remove the contaminant even at very low concentration [17-19]. However, the choice of the adsorbent is based on economical and practical reasons. Clay is one of the well-known low-cost natural clay materials, available worldwide in rocks. Among clays, the kaolin may be a good alternative low-cost adsorbent because it is the most abundant kaolinite-rich rock in Algeria. Indeed, Algeria possesses in the East, an estimated amount of millions of tons of clays that need to be promoted. Thus, the kaolin with low-cation exchange capacity (CEC $=3-15 \mathrm{meq} / 100 \mathrm{~g}$ ) is a convenient adsorbent for removing organic, inorganic pollutants and of heavy metal ions from water [20-24]. Acid activation can improve the adsorption performance of clay to increase its specific area $[25,26]$. Few studies are carried out with adsorption of anionic dyes on local kaolin DD3 and KT2.

The aim of the present work is to investigate the adsorption of anionic reactive dye (Derma Blue R67) which is commonly used in the Algerian tanning industry, onto Algerian clays from Djebel Debagh and El Milia regions. In addition, for a successful scale-up of such adsorption process, kinetic studies are essential since they describe the adsorbate removal rate, which in turn controls the residence time in the adsorbent-solution interface. A number of experimental parameters are considered in this study, including the effect of initial dye concentration, initial solution, $\mathrm{pH}$, acid activation, dose of adsorbent and nature of clays.

\section{Materials and methods}

\subsection{Materials}

Two commercial raw clay materials, DD3 and KT2, were supplied by a ceramic company (ETER, Guelma, Algeria). The kaolin "DD3", grey in colour, was sampled in an active kaolin mine, formed by hydrothermal alteration processes in the region of Guelma (Djebel Debagh, Algeria) [27,28]. This clay composed of halloysite and kaolinite with a ratio halloysite/ kaolinite $=1.23$, is a potential adsorbent in mortars [29] and for metals [30]. The second clay material "KT2" is also composed of kaolinite and halloysite, and already enriched in clay minerals by the ceramic company (ETER), by removing other minerals. It comes from El Milia deposit "TAMAZERT" from Jijel region (Algeria). The El Milia region consists of metamorphic rocks belonging to the Precambrian. The kaolin deposit is the alteration zone of gneiss, and is often in contact with mica schist.

It should be noted that the most important members of the kaolin subgroup of minerals are kaolinite and halloysite. Kaolinite has the formula $\mathrm{Al}_{2} \mathrm{Si}_{2} \mathrm{O}_{5}(\mathrm{OH})_{4}$ and typically occurs in platy forms. Halloysite has a similar composition except that it contains additional water molecules between the layers and most commonly has a tubular morphology. Halloysite loses its interlayer water very easily, so it is often observed in a partly dehydrated state. In its fully hydrated form the formula is $\mathrm{Al}_{2} \mathrm{Si}_{2} \mathrm{O}_{5}(\mathrm{OH})_{4} 2 \mathrm{H}_{2} \mathrm{O}$. Kaolinite is a very important industrial mineral, and halloysite is becoming increasingly important due mainly to its use in nanotechnology applications which take advantage of its tubular habit.

The reactive dye used as adsorbate is a bifunctional dye, soluble in water, commonly in use in the tanning industry. It was provided by the Cromogenia Company (Spain) and its commercial name is Derma Blue R67. The complete structure diagram of the dye is not available. A synthetic test dye solution was prepared by dissolving accurately weighed amounts of dye $(1 \mathrm{~g} / \mathrm{L})$ in distilled water and subsequently diluted to the required concentrations. The $\mathrm{pH}$ value of the initial dye aqueous solutions was measured at $25^{\circ} \mathrm{C}$ with a Consort C831 potentiometer.

\subsection{Clay preparation and characterization methods}

In order to obtain the acid-activated clays DD3 and KT2, the acid treatment was carried out with $0.1 \mathrm{~N} \mathrm{H}_{2} \mathrm{SO}_{4}$ acid [31]. We added $5 \mathrm{~g}$ of natural clay (DD3 or KT2) to $100 \mathrm{~mL}$ of the $0.1 \mathrm{~N} \mathrm{H}_{2} \mathrm{SO}_{4}$ aqueous solution and agitation was applied during $4 \mathrm{~h}$. The solution was filtered and then washed several times with distilled water. The filtrate was put in a drying oven for $12 \mathrm{~h}$ at approximately $60^{\circ} \mathrm{C}$. After drying and crushing in a mortar, very fine particles were obtained. The CEC was measured in order to evaluate the potential adsorption sites of the clays. It was determined using the Hexammine cobalt (III) chloride saturation method coupled with UV-VIS spectrophotometry Photolab Spectral WTW. The chemical composition of the clays was measured by X-ray fluorescence. The $\mathrm{pH}$ of the solution was adjusted with a $\mathrm{NaOH}$ or $\mathrm{HCl} 0.1 \mathrm{M}$ solution using "HANNA Instruments" (Guelma, Algeria) model pH meter that was equipped with a combined $\mathrm{pH}$ electrode. $\mathrm{X}$-ray diffraction (XRD) of the random-powdered clays before and after activation was carried out by using the XRD instrument (X-Pert Pro PANalytical, Strasbourg, France) with $\mathrm{CuK} \alpha$ radiation source $(\lambda=1.54056 \AA)$, and recorded in the $2 \theta$ ranging from $6^{\circ}$ to $65^{\circ}$ with a scanning rate of $1 \%$ min under the controlling of $40 \mathrm{kV}$ and $30 \mathrm{~mA}$. The following diagnostic treatments were performed for parallel-oriented specimens of the clays: ethylene glycol and hydrazine solvations overnight, and heating at $490^{\circ} \mathrm{C}$ for $4 \mathrm{~h}$. Measurements were carried out by XRD on a Bruker D5000 $\left(2^{\circ}-30^{\circ} 2 \theta\right.$ scanning angle $)$ and the program MacDiff (version 4.2) was used to estimate the relative contents of each clay mineral species based on the area of their (001) basal reflections [32]. Surface morphology of DD3 and KT2 natural and modified clays were investigated by scanning electron microscopy (SEM; JSM-6390 LU, JEOL, Biskra, Algeria) operating at $5-30 \mathrm{kV}$. To examine these clays, the samples were coated with a conducting layer of gold and carbon 
by sputter coating. The surface area of all samples was measured by adsorption of nitrogen at liquid nitrogen temperature according to the Brunauer, Emmett et Teller (BET) method, using ASAP, Micromeritics (Guelma, Algeria). The points of zero net proton charge were determined from potentiometric titration at different ionic strengths [33]. Electrophoretic mobilities of the clay particles were measured at $20^{\circ} \mathrm{C} \pm 2^{\circ} \mathrm{C}$ by using a zetaphoremeter as described elsewhere [34].

\subsection{Adsorption studies}

The adsorption experiments were performed in batch to assess the adsorptive capacities of natural and synthetic adsorbents, and to obtain the rate and the equilibrium data. Adsorption of the dye from water onto the clay samples was carried out in $500 \mathrm{~mL}$ conical flasks, filled with various dye concentrations ranging from 20 to $200 \mathrm{mg} / \mathrm{L}$, containing $4 \mathrm{~g}$ of clay (DD3, KT2), and agitated at a constant stirring speed of $450 \mathrm{rpm}$ at natural $\mathrm{pH}$ (4.0) for $120 \mathrm{~min}$. Aliquots of $2 \mathrm{~mL}$ of the solution were sampled at suitable time intervals. The samples were then centrifuged for $15 \mathrm{~min}$ at 5,000 rpm, and the left out concentrations in the supernatant solution were analyzed. The equilibrium concentrations of dye were determined by measuring the absorbance at the maximum wavelength of the dye $(610 \mathrm{~nm}$ for Derma Blue $\mathrm{R} 67$ at $\mathrm{pH}=5.6$ ) with an UV-vis spectrophotometer (Photolab Spectral WTW). In the kinetic experiments, the amount of dye adsorbed at a time interval $t, Q_{t}(\mathrm{mg} / \mathrm{g})$, or the percentage removal $(P \%)$ were calculated using the following equations:

$Q_{t}=\left(C_{0}-C_{t}\right) V / m$

$P \%=100\left(C_{0}-C_{t}\right) / C_{i}$

where $C_{0}$ and $C_{t}$ are the initial and liquid-phase concentrations of the dye solution $(\mathrm{mg} / \mathrm{L})$ at any time $t$, respectively, $V$ is the volume of dye solution (L), and $m$ is the mass of clay sample used (g). The effect of $\mathrm{pH}$ on the removal of the dye was investigated by mixing $500 \mathrm{~mL}$ of the dye solution with $4 \mathrm{~g}$ of clay in a solution with an initial dye concentration of $20 \mathrm{mg} / \mathrm{L}$ at $20^{\circ} \mathrm{C}$ for $120 \mathrm{~min}$ with constant agitation, and over a pH range of 3-9. The effect of the initial dye concentration on dye removal was investigated by mixing $500 \mathrm{~mL}$ of the dye solution with $4 \mathrm{~g}$ of solid without adjusting the $\mathrm{pH}$ at $20^{\circ} \mathrm{C}$ for $120 \mathrm{~min}$ with agitation. The initial dye concentrations were varied from 20 to $200 \mathrm{mg} / \mathrm{L}$. Different amounts of the adsorbent $(0.5-8 \mathrm{~g})$ were used to examine the effect of the adsorbent dosage on the adsorption of the dye. All the experiments were performed in duplicate.

\section{Results and discussion}

\subsection{Characterization of the adsorbent}

The chemical composition indicated that the raw clays were rich in $\mathrm{Si}, \mathrm{Al}$ and contained only small amounts of $\mathrm{Fe}$, $\mathrm{Ca}, \mathrm{Mg}$, Na and $\mathrm{K}$ (Table 1).

The low concentrations of these elements confirm the high content of the raw clay material in kaolin-type minerals. That high degree of purity of the clay material generates the rheological and physico-chemical properties of the raw
Table 1

Chemical compositions of DD3 and KT2 raw clays expressed in mass percentage of oxides (wt \%)

\begin{tabular}{lcc}
\hline Clays & DD3 & KT2 \\
\hline $\mathrm{SiO}_{2}$ & 41.97 & 49.30 \\
$\mathrm{Al}_{2} \mathrm{O}_{3}$ & 38.00 & 33.50 \\
$\mathrm{Fe}_{2} \mathrm{O}_{3}$ & 0.12 & 1.59 \\
$\mathrm{MgO}$ & 0.07 & 0.40 \\
$\mathrm{CaO}$ & 0.20 & 0.08 \\
$\mathrm{Na}_{2} \mathrm{O}$ & - & 0.09 \\
$\mathrm{~K}_{2} \mathrm{O}$ & - & 2.75 \\
$\mathrm{NO}_{2}$ & - & - \\
$\mathrm{TiO}_{2}$ & - & 0.24 \\
$\mathrm{BaO}_{\mathrm{SO}}$ & - & - \\
$\mathrm{SnO}_{3}$ & 0.75 & - \\
$\mathrm{MnO}$ & 1.34 & - \\
\hline
\end{tabular}

material, required in the ceramic industry. The apparent values of the point of zero charge (PZC) of the various clay amphoteric surfaces, in their natural state, were determined for two ionic forces. It should be noted that it was not possible to determine a clear common intercept point [33] of the potentiometric titration curves at the two ionic strengths.

The DD3 clay exhibits high apparent PZC value (5.3-7.3) compared with the apparent PZC of the KT2 clay (4.5-6.2) and the standard KGa-2 sample (3.4) (Tunisian clay commonly called Fouchana clay). This indicates that the DD3 natural clay may present positive adsorption sites at particle edges available for anionic dyes, already at $\mathrm{pH}$ between 5.3 and 7.3, unlike the KT2 clay which needs lower $\mathrm{pH}$ values to enhance the adsorption of anions. The BET specific surface area $\left(S_{\mathrm{BET}}\right)$, the CECs and the pore diameter (Dp) of the raw and activated clays were also determined. The CEC was measured in order to evaluate the potential use of these clays for the adsorption of cations. After the activation of the KT2, and the DD3 samples, the CEC values decreased, respectively, from 30 to 15 , and from 15 to 9 (meq/100 g). However, the activation of the KT2 and DD3 samples, lead to an increase of their $S_{\text {BET }}$ values, respectively, from 24 to 31 and from 49 to $65 \mathrm{~m}^{2} / \mathrm{g}$, suggesting hence an increase in their available adsorption sites. The higher $S_{\mathrm{BET}}$ value for the activated DD3 $\left(65 \mathrm{~m}^{2} / \mathrm{g}\right)$, as compared with the activated KT2 $\left(31 \mathrm{~m}^{2} / \mathrm{g}\right) \mathrm{sug}$ gests a pronounced acid activation of the DD3 sample and development of surfaces at the expense of the pore sizes which slightly decrease.

The XRD results for DD3 and KT2 clays before and after activation are shown in Fig. 1 . The basal spacings or $\mathrm{d}_{001}$ spacings of DD3 clay of $7.14 \AA$ and $7.35 \AA$ may be attributed to kaolinite and dominant halloysite, respectively (Figs. 1(a) and (b)). The basal spacings or $\mathrm{d}_{001}$ spacing values of KT2 are similar to those of DD3, but with intensities indicating a dominance of kaolinite. Other reflections attributed to quartz, calcite as impurities are observed for both natural kaolins, as also minor amounts of illite. Moreover, there are traces of smectite and interstratified illite/smectite in KT2 clay. The slight increase of the basal spacings in the activated DD3 (7.33 $\AA$ ) and KT2 (3.59 $\AA$ ) clays (Figs. 1(b) and (d)) after ethylene glycol treatment indicate that the acid treatment 

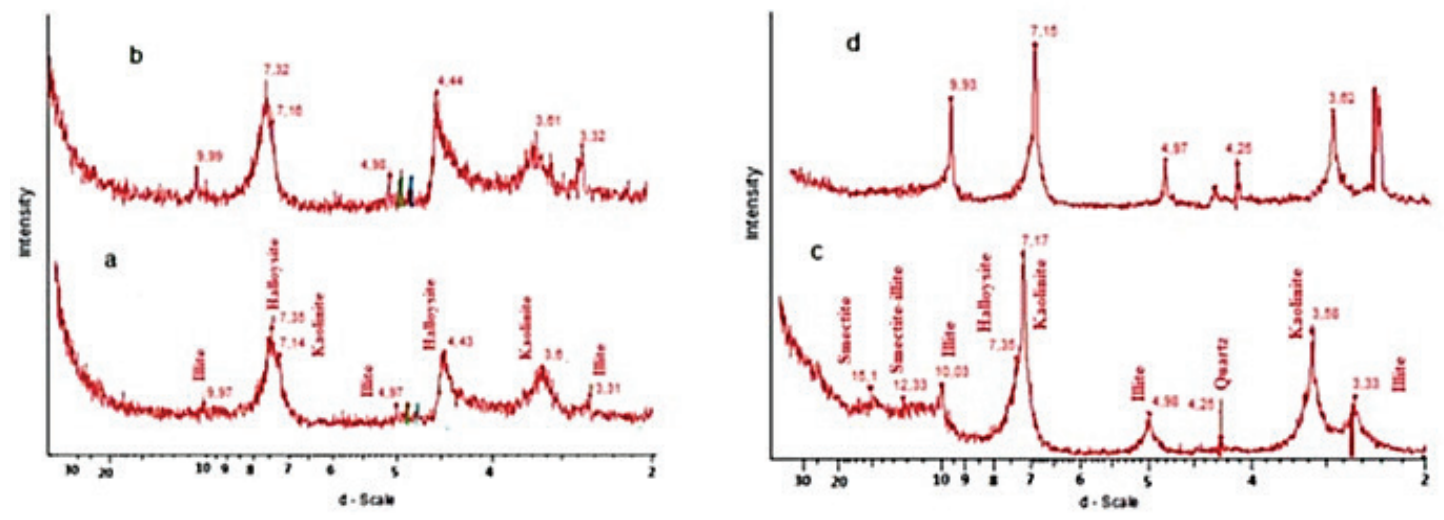

Fig. 1. XRD patterns of the natural and activated clays: (a) and (c): respectively, natural DD3 and KT2; (b) and (d): respectively, activated DD3 and KT2 samples.

affected the structure of the components and that the interlayer spaces expanded. Furthermore, acid treatment with $\mathrm{H}_{2} \mathrm{SO}_{4} 0.1 \mathrm{~N}$, dissolved the major impurities such as calcite, quartz and dolomite for both materials, and the traces of smectite, and interstratified illite/smectite in KT2. Thus, illite shows a higher crystallinity in KT2.

\subsection{Adsorption studies}

\subsubsection{Effect of contact time and initial dye concentration}

The initial concentration of the dye is an important driving force to overcome the mass transfer resistance of the dye from the aqueous and the solid phase. The amounts of dye removed by the activated DD3 and KT2 clays, as a function of the initial concentration of the dye, were determined (Fig. 2). The shapes of the curves for DD3 and KT2 clays are similar and approximately independent on the initial dye concentration. These data indicate a monolayer formation of the dye on the external clay surface [35]. It should be noted that both clays are efficient to adsorb Derma Blue R67 with different rates. The adsorption of the dye from water onto the activated DD3 and KT2 clays was rapid in the first $2 \mathrm{~min}$, followed by a slow increase until reaching equilibrium after about $10 \mathrm{~min}$. At the beginning, the adsorption rate was very fast as the dye ions were adsorbed on the external surfaces of the clay, until they reached saturation. Then the dye ions entered into the pores of the adsorbent particles and were adsorbed by the internal surfaces of the solid particles. This process took a relatively short time and the adsorption was slow. The adsorption capacity increased with increasing initial dye concentration. A similar trend was reported for the adsorption of dyes such as Malachite Green onto treated sawdust [36], reactive dyes onto dried activated sludge [37] and anionic dye (Reactive Red 120) on Fouchana clay [38].

\subsubsection{Effect of the $p H$}

The $\mathrm{pH}$ is an important parameter modulating the dye adsorption efficiency $[39,40]$. The effects of the aqueous phase $\mathrm{pH}$ on the DD3 and KT2 adsorption capacities were investigated at $\mathrm{pH}$ values ranging from $\mathrm{pH}=3.0$ to 9.0, and at temperature $T=20^{\circ} \mathrm{C}$ (Fig. 3). Generally, at low pH
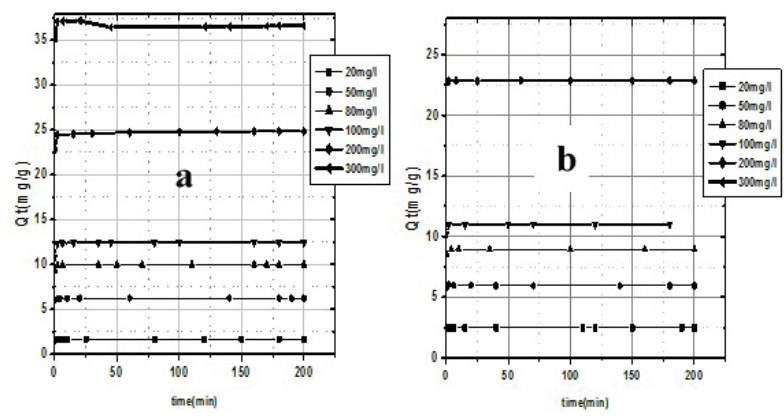

Fig. 2. Effect of contact time and initial dye concentration on the adsorption rate of Derma Blue R67 on activated clays (a) DD3, (b) $\mathrm{KT} 2 ; m=4 \mathrm{~g}, \mathrm{pH}=6.2, \mathrm{~T}=20^{\circ} \mathrm{C}$ ).

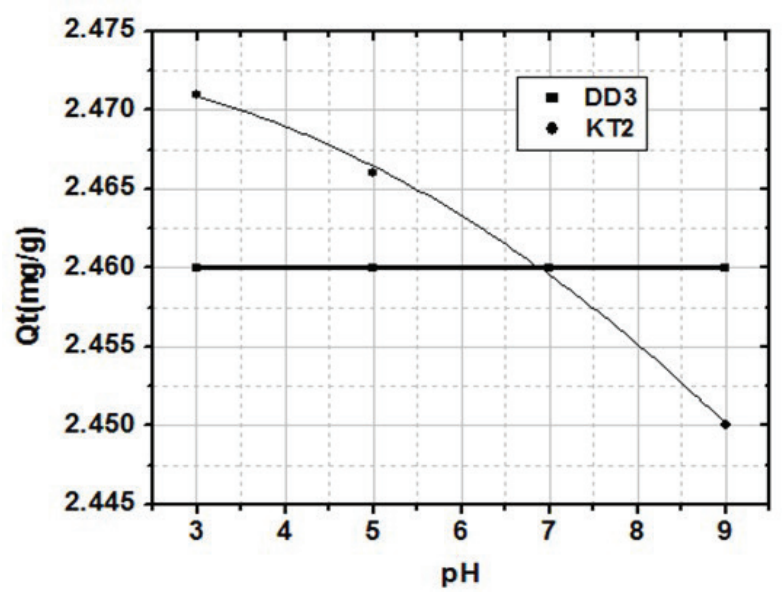

Fig. 3. Effect of the $\mathrm{pH}$ on the adsorption of Derma Blue R67 on activated DD3 and KT2 $\left(m=4 \mathrm{~g}, C_{0}=20 \mathrm{mg} / \mathrm{L}, T=20^{\circ} \mathrm{C}\right)$.

values, the percentage of the cationic dye removal is lower, and higher for the anionic dye, due to creation of positively charged adsorption sites on the clay surface at acidic $\mathrm{pH}$ values. The reverse is observed at higher $\mathrm{pH}$ values. The data obtained in the present work indicate that the adsorption of Derma Blue R67 dye on DD3 clay is unaffected by $\mathrm{pH}$ over the whole range explored, and an average 
value of $2.5 \mathrm{mg} / \mathrm{g}$ was observed for the adsorbed amount $Q_{t}$. This may suggest that the dye adsorption from water onto DD3 may have mainly occurred on sites which are not $\mathrm{pH}$ dependent, whereas onto the KT2 clay, the adsorption enhancement at low $\mathrm{pH}$ was related to the solid surface amphoteric sites. Similar results were reported for the adsorption of anionic dyes by cross-linked cationic starch $[41,42]$ and cross-linked quaternary chitosan [43]. The maximum uptake of Derma Blue R67 on KT2 was found to be at $\mathrm{pH}$ 2. This behaviour can be explained on the basis of changes in the surface charge of KT2's amphoteric sites. At lower $\mathrm{pH}$, the $\mathrm{H}^{+}$ion concentration in the aqueous medium increased, and the surface of KT2 acquires positive charge by absorbing $\mathrm{H}^{+}$ions. The positively charged surface sites on KT2 favour the adsorption of anionic dye due to the electrostatic attraction, causing an increase in the dye adsorbed amount. As the $\mathrm{pH}$ of the aqueous phase increases, the numbers of negatively charged sites increase by absorbing $\mathrm{OH}^{-}$ions. As the KT2 surface gets negatively charged at high $\mathrm{pH}$, a significantly high electrostatic repulsion exists between the negatively charged surface of KT2 and anionic dye molecules, leading to a decrease in dye adsorption. Similar results were reported for the adsorption of anionic dyes by cross-linked cationic starch [42], cross-linked quaternary chitosan [43], by pullulan microspheres [44], and by diphosphonium-intercalated montmorillonite.

\subsubsection{Effect of the clay amount}

The effect of clay amount on the adsorption of Derma Blue R67 was also evaluated at temperature $T=20^{\circ} \mathrm{C}$ (as shown in Fig. 4). Hence, the adsorbent dosage varied from 0.5 to $8 \mathrm{~g}$ with a fixed initial dye concentration of $20 \mathrm{mg} / \mathrm{L}$, at $\mathrm{pH}$ 4.0. We observed initially, a rapid increase in the dye adsorbed amount, $Q_{t}$, with the increase of the adsorbent dosage, as resulting from the increase of the solid adsorption sites number. In the presence of $1.5 \mathrm{~g}$ of the adsorbent, the removal of the dye from the solution was almost completely achieved (99\%). However, on increasing the adsorbent amount, there is no improvement of the dye removal from water, which means that 1.5 and $4 \mathrm{~g}$, of DD3 and KT2, respectively, are the optimal amounts of clays necessary to remove the dye at a concentration of $20 \mathrm{mg} / \mathrm{L}$. A similar behaviour was observed for cationic starch derivatives [45] and anionic dyes (Azocarmine B, Acid Orange 7, Methyl Orange, Ponceau 6R and Congo Red) adsorbed on pullulan microspheres [44].

\subsubsection{Effect of the temperature on the dye adsorbed amount and evaluation of the thermodynamic parameters}

Temperature is one of the most important factors in adsorption process. This was investigated for the adsorption of Derma Blue R67 dye onto activated clays as a function of temperature $\left(20^{\circ} \mathrm{C}-50^{\circ} \mathrm{C}\right)$ (Table 2). Generally, temperature has two major effects on the adsorption process. Increasing the temperature induces an increase in the diffusion rate of adsorbate molecules onto the adsorbent surface, thereby diminishing mass transfer resistance in liquid phase as a result of the reduced viscosity of bulk solution [46].

The amount of Derma Blue R67 dye adsorbed onto activated KT2 and DD3 clays (Fig. 5) increases slightly with the
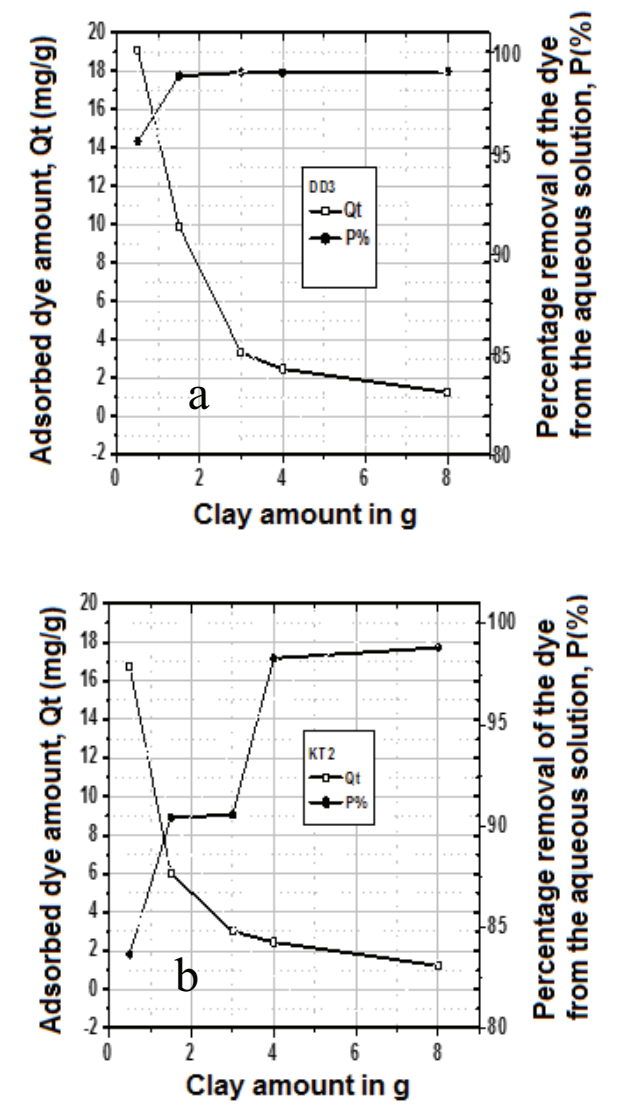

Fig. 4. Effect of clay amount on the adsorption of Derma Blue R67 on activated DD3 (a) and KT2 (b) clays $\left(C_{0}=20 \mathrm{mg} / \mathrm{L}\right.$, $\left.\mathrm{pH}=6.2, \mathrm{~T}=20^{\circ} \mathrm{C}\right)$.

Table 2

Thermodynamic parameters for the adsorption of Derma Blue R67 onto activated KT2 and DD3 clays at different temperatures (without control of the $\mathrm{pH}$ )

\begin{tabular}{|c|c|c|c|c|c|c|c|c|c|c|}
\hline \multicolumn{2}{|l|}{ Clays } & \multicolumn{5}{|l|}{ DD3 } & \multicolumn{4}{|l|}{ KT2 } \\
\hline$T\left({ }^{\circ} \mathrm{K}\right)$ & $\begin{array}{l}Q_{t} \\
(\mathrm{mg} / \mathrm{g})\end{array}$ & $\ln K_{c}$ & $\begin{array}{l}\Delta G^{\circ} \\
(\mathrm{kJ} / \mathrm{mol})\end{array}$ & $\begin{array}{l}\Delta H^{\circ} \\
(\mathrm{kJ} / \mathrm{mol})\end{array}$ & $\begin{array}{l}\Delta S^{\circ} \\
(\mathrm{kJ} / \mathrm{mol})\end{array}$ & $\begin{array}{l}Q_{t} \\
(\mathrm{mg} / \mathrm{g})\end{array}$ & $\ln K_{c}$ & $\begin{array}{l}\Delta G^{\circ} \\
(\mathrm{kJ} / \mathrm{mol})\end{array}$ & $\begin{array}{l}\Delta H^{\circ} \\
(\mathrm{kJ} / \mathrm{mol})\end{array}$ & $\begin{array}{l}\Delta S^{\circ} \\
(\mathrm{kJ} / \mathrm{mol})\end{array}$ \\
\hline 293 & 2.37 & -0.08 & 0.19 & 0.56 & 1.28 & 2.25 & 1.42 & -3.45 & 14.18 & 59.8 \\
\hline 303 & 2.48 & -0.07 & 0.17 & & & 2.26 & 1.50 & -3.78 & & \\
\hline 313 & 2.49 & -0.06 & 0.16 & & & 2.26 & 1.72 & -4.48 & & \\
\hline 323 & 2.50 & -0.055 & 0.15 & & & 2.27 & 1.95 & -5.24 & & \\
\hline
\end{tabular}



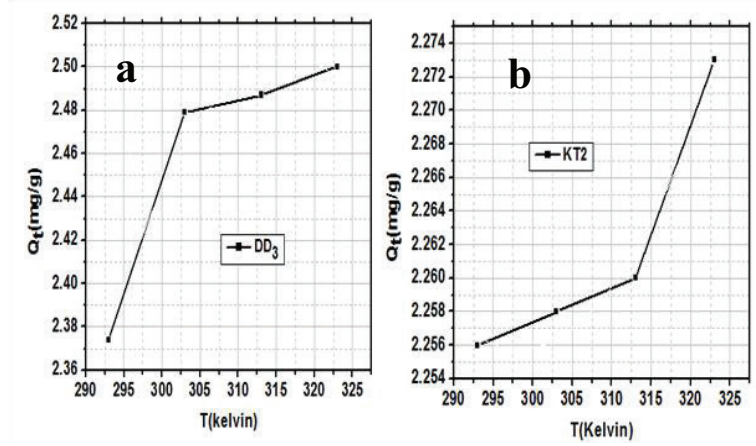

Fig. 5. Effect of temperature on the adsorption of Derma Blue R67 on activated kaolins (a) DD3 and (b) KT2 ( $m=4 \mathrm{~g}, \mathrm{C}_{0}=20 \mathrm{mg} / \mathrm{L}$, $\mathrm{pH}=4)$.

increase in temperature (Table 2). This may be due to increasing the mobility of the dye molecules, and an increased access to the active sites for the adsorption with increasing temperature [47].

Thermodynamic parameters such as standard free energy change $\left(\Delta G^{\circ}\right)$, enthalpy change $\left(\Delta H^{\circ}\right)$ and entropy change $\left(\Delta S^{\circ}\right)$ were calculated using the following equations $[48,49]$ :

$$
K_{c}=\frac{C_{e}}{\left(C_{i}-C_{e}\right)}
$$

$\Delta G^{\circ}=-R T \ln K_{c}$

And the Van't Hoff equation:

$\ln K_{c}=\left(\Delta S^{\circ} / R\right)-\left(\frac{\Delta H^{\circ}}{R T}\right)$

where, $K_{c}(\mathrm{~L} / \mathrm{mg})$ is the equilibrium constant; $q_{e}$ and $C_{e}$ are the equilibrium concentrations of adsorbate in the liquid phase $(\mathrm{mg} / \mathrm{L})$ and on the solid phase $(\mathrm{mg} / \mathrm{g})$, respectively; $T$ is the temperature in Kelvin and $R$ is the gas constant $(8.314 \mathrm{~J} / \mathrm{mol} \mathrm{K})$. The values of the enthalpy $\left(\Delta H^{\circ}\right)$ and entropy $\left(\Delta S^{\circ}\right)$ were determined, respectively, from the slope and intercept of the plot of $\ln K_{c}$ vs. $1 / T$. As can be seen from Table 2, the Gibbs free energy of adsorption $\left(\Delta G^{\circ}\right)$ is slightly positive, very close to 0 for DD3, and slightly negative for KT2. In both cases, $\Delta G^{\circ}$ slightly decreases when $T$ increases, suggesting that the adsorption process is possible at ambient temperature but more spontaneous at higher temperature, especially for KT2, despite a small increase in the adsorbed amount.

The values of the change in enthalpy $\left(\Delta H^{\circ}\right)$ were positive, which show that the process is endothermic in nature. The positive values of $\Delta S^{\circ}$ reflect increased randomness at the solid-solution interface during dye adsorption.

As can be seen from Table 2, the Gibbs free energy of adsorption $\left(\Delta G^{\circ}\right)$ is slightly positive, very close to 0 for DD3, and slightly negative for KT2. In both cases, $\Delta G^{\circ}$ value slightly decreases when $T$ increases, suggesting that the adsorption process is possible at ambient temperature but more spontaneous at higher temperature, especially for KT2, despite a small increase in the adsorbed amount. In general, the increase in temperature weakens the attractive forces of physical or chemical nature, which is frequently observed in the adsorption phenomena [50]. If the adsorption capacity increases with increasing temperature, adsorption is an endothermic reaction $\left(\Delta H^{\circ}>0\right)$. This may be due to increased mobility of dye molecules and an increase in the number of active sites for adsorption as the temperature increases [44].

The adsorption increase in the temperature range of $20^{\circ} \mathrm{C}-50^{\circ} \mathrm{C}$ means that the adsorption process of the Derma blue R67 dye by the activated DD3 and KT2 clays is endothermic.

\subsubsection{Adsorption isotherms}

The adsorption isotherm indicates how the adsorbate molecules are distributed between the liquid and the solid phases when the adsorption process reaches an equilibrium state [51]. The isotherm data were analyzed by fitting them to the Langmuir and the Freundlich isotherm models [52,53]. These models are described in Eqs. (6) and (7), respectively:

Langmuir equation:

$\frac{1}{q_{e}}=\frac{1}{q_{m}}+\frac{1}{q_{m}} b \cdot \frac{1}{C_{e}}$

where $C_{e}$ is the equilibrium concentration $(\mathrm{mg} / \mathrm{L}), q_{e}$ is the amount adsorbed at equilibrium $(\mathrm{mg} / \mathrm{g}), q_{m}$ is the maximum amount adsorbed $(\mathrm{mg} / \mathrm{g})$ and $b$ is the energy of adsorption (Langmuir constant, $\mathrm{L} / \mathrm{mg}$ ). The values of $q_{m}$ and $b$ were calculated from the slope and intercept of the linear plot $C_{e} / q_{e}$ vs. $C_{e}$. The slope $1 / q_{m}$ corresponds to the complete monolayer coverage $(\mathrm{mg} / \mathrm{g})$ and the intercept is $1 /\left(q_{m} b\right)$.

Freundlich equation:

$\ln q_{e}=\ln K_{F}+\frac{1}{n} \ln C_{e}$

where $K_{F}$ and $n$ are Freundlich constants, calculated from the slope and intercept of the Freundlich plot. It has been shown that an $n$ value between 1 and 10 represents a good adsorption potential of the adsorbent. Hence, the experimental data were adjusted to the Langmuir and Freundlich models and the isotherm constants were then determined as shown in Table 3.

Our results indicate that the Langmuir model gives the best fit to the experimental data for both DD3 and KT2 clays, which means that the dye molecules form a monolayer on the clay surface. Furthermore, the Freundlich exponent $1 / n$ gives an indication on the preferential dye adsorption from water onto the clay surface. Hence, according to Freundlich model, values of $1 / n<1.0$ represent favourable adsorption conditions. In the present study, as indicated in Table 3, all the values of $1 / n$ were less than unity, indicating preferential adsorption of Derma Blue onto the DD3 and KT2 samples [54].

\subsubsection{Adsorption kinetics}

The solute uptake rate is an important parameter in the understanding of the kinetic mechanism which controls the 
adsorption of the dye onto activated DD3 and KT2 clays. This was evaluated using the pseudo-first order [55], the pseudo-second order [56,57], the intra-particle diffusion [58] and the Elovich models according to Eqs. (8)-(11):

$$
\begin{aligned}
& \log \frac{\left(q_{e}-q_{t}\right)}{q_{e}}=-\frac{K_{1} t}{2,3} \\
& \frac{t}{q_{t}}=\frac{1}{2 K_{2} q_{e}^{2}}+\frac{t}{q_{e}} \\
& q_{t}=K_{i} t^{1 / 2}+C
\end{aligned}
$$

where $q_{t}$ and $q_{e}$ represent the amounts of the adsorbed dye at time $t$ and at equilibrium $(\mathrm{mg} / \mathrm{g})$, respectively; $K_{1}(1 / \mathrm{min})$, $K_{2}(\mathrm{~g} / \mathrm{mg} \mathrm{min})$ and $K_{i}\left(\mathrm{mg} / \mathrm{g} \mathrm{min}^{1 / 2}\right)$ are the rate constants, respectively, for the pseudo-first order, the pseudo-second order and the intra-particle diffusion models, for the adsorption process; $t$ is the time ( $\mathrm{min}$ ) and $C$ is the intercept on the $y$-axis $(\mathrm{mg} / \mathrm{g})$.

\section{Table 3}

Langmuir and Freundlich isotherm constants for the adsorption of Derma Blue R67 on the KT2 and DD3 clays (adsorbent amount

\begin{tabular}{|c|c|c|c|}
\hline Models & Equations & Clay type & Parameters \\
\hline \multirow[t]{6}{*}{ Langmuir } & $1-1,1$ & DD3 & $q_{m}=38.46$ \\
\hline & $\overline{q_{e}}=\overline{q_{m}}+\overline{q_{m} b} \overline{C_{e}}$ & & $b=0.24$ \\
\hline & & & $R^{2}=0.99$ \\
\hline & & KT2 & $q_{m}=5.58$ \\
\hline & & & $b=0.33$ \\
\hline & & & $R^{2}=0.92$ \\
\hline \multirow[t]{6}{*}{ Freundlich } & & DD3 & $K_{F}=0.79$ \\
\hline & $\ln q_{e}=\ln K_{F}+\frac{-}{n} \ln C_{e}$ & & $1 / n=0.312$ \\
\hline & & & $R^{2}=0.74$ \\
\hline & & KT2 & $K_{F}=1.27$ \\
\hline & & & $1 / n=0.520$ \\
\hline & & & $R^{2}=0.89$ \\
\hline
\end{tabular}
$4 \mathrm{~g}, 20.0 \mathrm{~mL}$ of $20-200 \mathrm{mg} / \mathrm{L}$ dye solution, without control of $\mathrm{pH}$, agitation time of $120 \mathrm{~min}$ )
The pseudo-first-order kinetic model describes the adsorption of a solute from liquid solution $[55,56]$ and is nowadays widely used in different fields of pollutants adsorption from wastewater. The pseudo-second order model assumes that the chemisorption is the mechanism of the adsorption of adsorbate on the adsorbent. The values of the parameters obtained from the analysis of data according to the investigated kinetic models are shown in Table 4. The coefficient of determination $R^{2}$ was calculated, to evaluate the most appropriate model adjusting the data. The Elovich equation is often used when the adsorbing surface is heterogeneous. The linear form of Elovich equation is given as follows [59]:

$q_{t}=\frac{1}{\beta}(\alpha \beta)+\frac{1}{\beta} \ln t$

where $\alpha(\mathrm{mg} / \mathrm{g} \mathrm{min})$ is the initial adsorption rate constant and the parameter $\beta(\mathrm{g} / \mathrm{mg})$ is related to the extent of surface coverage and activation energy for chemisorption. The values of $\alpha$ and $\beta$ can be calculated from the plot of $q_{t}$ against $\ln t$. The values of the constants $\alpha$ and $\beta$ are given in Table 4 .

The $R^{2}$ values for both clays were found to be higher for the pseudo-first order and pseudo-second order models than those obtained for the Elovich model and intra-particle diffusion models. The pseudo-second order and the pseudo-first order models describe and fit the experimental data very well, for activated KT2. However, for activated DD3, only the pseudo-second order model yielded the best fit of the experimental data. Therefore, the adsorption of Derma Blue R67 onto DD3 kaolin can be explained by a chemical sorption process, whereas onto KT2 clay it may involve two processes. Similar studies on the adsorption of anionic dyes by clays have found that the pseudo-second order model is the most reliable for determining adsorption kinetics [38,60-62].

\subsection{Electrophoretic mobilities of DD3 and KT2 clays}

The electrophoretic mobilities were measured for both activated and non-activated DD3 and KT2 clays, before and after adsorption of the blue dye, in order to determine the surface charge of the clay particles and its evolution in function of $\mathrm{pH}$ (Figs. 6(a) and (b), and 7(a) and (b)).

The results indicate that several factors affect the electrophoretic mobility of the clays:

\begin{tabular}{|c|c|c|c|c|c|}
\hline Models & & Pseudo-first order & Pseudo-second order & Intra-particle diffusion & Elovich \\
\hline \multirow[t]{8}{*}{ Parameters } & DD3 & $K_{1}=+0.161$ & $K_{2}=376.135$ & $K_{i}=0.002$ & $\alpha=0.006$ \\
\hline & & $q_{m}=35.62$ & $q_{m}=2.37$ & $C=2.35$ & $\beta=166.66$ \\
\hline & & $R^{2}=0.81$ & $R^{2}=1$ & $R^{2}=0.75$ & $R^{2}=0.85$ \\
\hline & & & $q_{e}(\exp )=2.37$ & & \\
\hline & KT2 & $K_{1}=+0.958$ & $K_{2}=121.22$ & $K_{i}=0.01$ & $\alpha=0.005$ \\
\hline & & $q_{m}=2.181$ & $q_{m}=2.28$ & $C=2.154$ & $\beta=200$ \\
\hline & & $R^{2}=0.991$ & $R^{2}=1$ & $R^{2}=0.238$ & $R^{2}=0.533$ \\
\hline & & & $q_{e}(\exp )=2.27$ & & \\
\hline
\end{tabular}

Table 4

Kinetic parameters of the adsorption of the anionic Derma Blue R67 dye onto clays 

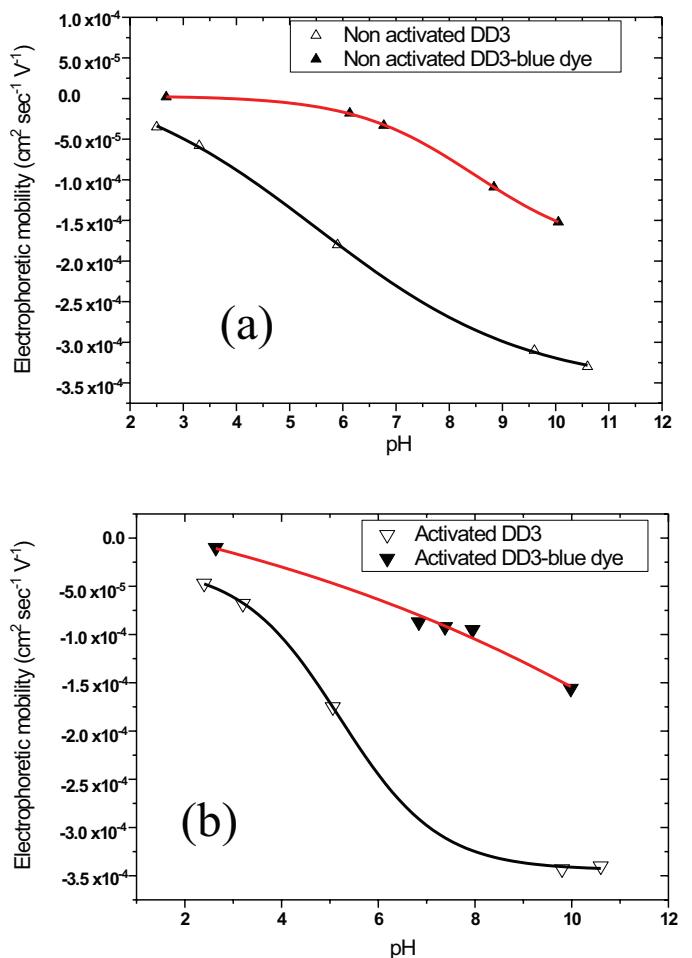

Fig. 6. (a). Electrophoretic mobilities vs. the aqueous phase $\mathrm{pH}$ of the non-activated DD3 clay before and after adsorption of the dye. (b) Electrophoretic mobilities vs. the aqueous phase $\mathrm{pH}$ of the activated DD3 clay before and after adsorption of the dye.

(1) The activation makes the clay more hydrophilic and increases its electrophoretic mobility in the whole $\mathrm{pH}$ range investigated.

(2) As can be seen in Figs. 6(a) and (b), and 7(a) and (b), the adsorption of dye decreases systematically the electrophoretic mobility magnitude of the both activated and non-activated clays. The adsorption of dye likely screens and/or reduces the electric charges of the clay.

(3) After adsorption of the dye, the electrophoretic mobility of the clay is higher for the activated as compared with the non-activated sample. This difference in behaviours results from the clay available adsorption sites created upon activation, and which remain uncovered by the dye molecules.

(4) The KT2 clay, whether activated or not, is more hydrophilic than the DD3 clay.

(5) The increase in the adsorption of the dye appears to be related to an increase in the specific surface area (due to the activation of the clay), or to an increase in the hydrophobicity of the clay. In fact, the DD3 sample (activated or not) is more hydrophobic than the KT2. Thus, DD3 has fixed more dye molecules than KT2 in both cases (activated and non-activated).

\subsection{Structure of clays after adsorption}

Observations by SEM were performed to probe the change in morphological features of activated DD3 and KT2 before and after dye adsorption (Derma Blue R67). The surface morphology of both clays before adsorption is different
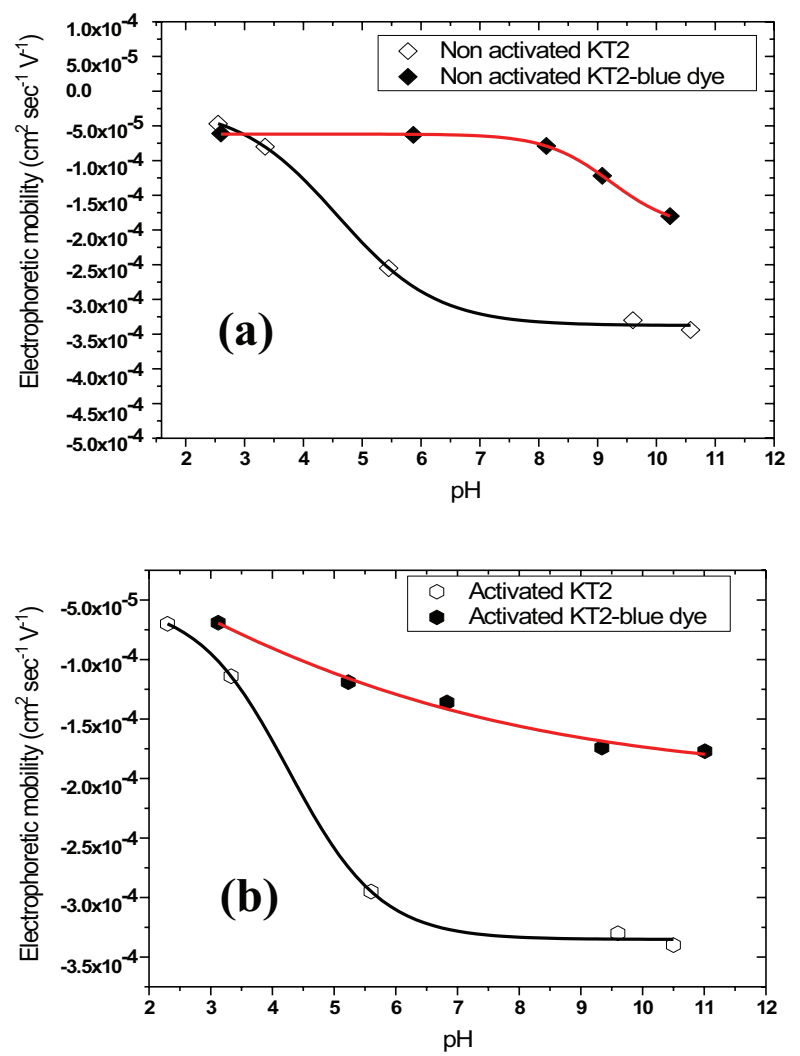

Fig. 7. (a) Electrophoretic mobilities vs. the aqueous phase $\mathrm{pH}$ of the non-activated KT2 clay before and after adsorption of Derma Blue R67. (b). Electrophoretic mobilities vs. the aqueous phase $\mathrm{pH}$ of the activated KT2 clay before and after adsorption of Derma Blue R67 dye.

from that after adsorption. Activated DD3 has larger pores between particles before adsorption than after adsorption (Figs. 8(a) and (b)). The same was also observed for the activated KT2 (Figs. 8(c) and (d)). Further, the micrographs shown in Figs. 8(b) and (d) indicate clearly the dye-loaded clay coated by dye molecules over the whole surface at natural $\mathrm{pH}$ conditions. The dye molecules seem to have formed a void-free film masking the reliefs of particles and porosity of the aggregates. On the contrary, the clay before adsorption exhibits well distinguishable particles and a porous structure (Figs. 8(a) and (c)). Moreover, upon the anionic dye adsorption on the clay particle, an increase in the clay particle size can be seen when comparing, respectively, Figs. 8(a) and (b) for the DD3 sample, and Figs. 8(c) and (d) for the KT2 sample. Such clay particle size increase results from the clay particle aggregation owing to the clay particles surface electric charge screening by the adsorbed dye molecules.

\section{Conclusion}

Two kaolinite and halloysite-rich kaolin clays, respectively, the DD3 (halloysite dominant) from Djebel Debagh (Guelma), and the KT2 (kaolinite dominant) from Tamazert (El Milia region), were activated, and their capacities were compared in the removal of effluents' Derma Blue R67 dye used in tannery. 

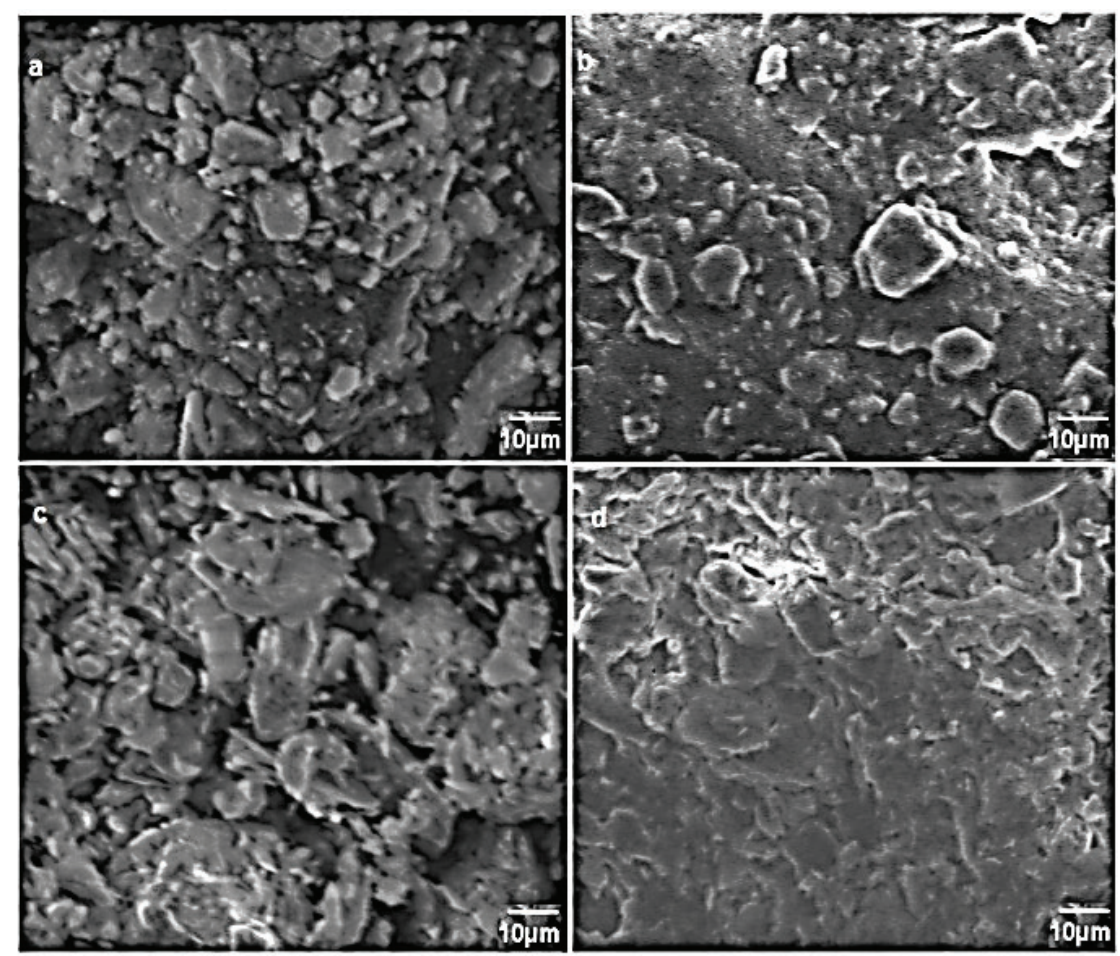

Fig. 8. SEM images of DD3 (a) and KT2 (c) activated clays before adsorption. SEM images of DD3 (b) and KT2 (d) activated clays after adsorption of Derma Blue R67 dye.

Both activated clays were efficient in the removal of the dye from aqueous solution. The synthetic effluent's discolouration by using the acid-activated DD3 sample was more pronounced and the clay surfaces were more developed, as compared with the KT2. The adsorption processes on both activated clays were possible at ambient temperature, slightly favoured by higher temperatures, and the process was endothermic in nature. Good agreement for DD3 was found between the experimental data and the predicted values obtained by using the Langmuir model, indicating the formation of a monolayer of the dye molecules on the clay surfaces. Moreover, the calculated positive values of the entropy's variations results likely from scarce disorder in the adsorbed dye molecules film at the solid-solution interface. The kinetic study indicates that the adsorption of Derma Blue R67 on the halloysite-rich DD3 clay is rather of chemical nature, whereas two types of processes may be involved in the adsorption onto the kaolinite-rich KT2 clay. The overall data show the high potential of the activated kaolin clays for the treatment of dyeing wastewater.

\section{Symbols}

$R \quad-\quad$ Gas constant

$T \quad-\quad$ Temperature

$t \quad-\quad$ Contact time adsorbate-adsorbent

$q_{t} \quad-\quad$ Amount of adsorbate in the adsorbent at any time $t$

$q_{e} \quad-\quad$ Amount of adsorbate in the adsorbent at equilibrium

$q_{m} \quad-\quad$ Maximum amount of adsorbate in the adsorbent
$Q_{t} \quad-\quad$ Adsorbed amount of the solute (the dye) on the solid surface at time $t$

$C_{i^{\prime}} C_{0}-$ Initial concentration of the solute (the dye)

$C_{t} \quad-\quad$ Liquid phase concentration of the solute (the dye) at any time $t$

$C_{e^{\prime}} C_{\mathrm{eq}}-$ Residual or equilibrium concentration of the solute (the dye)

C - Intercept of the $y$-axis in the intra-particle diffusion Eq. (10)

$K_{1} \quad-\quad$ Pseudo-first order rate constant of adsorption

$K_{2} \quad-\quad$ Pseudo-second order rate constant of adsorption

$K_{i} \quad-\quad$ Intra-particle diffusion rate constant

$K_{C} \quad-\quad$ Equilibrium constant

$K_{F} \quad-\quad$ Freundlich constant

$n \quad-\quad$ Freundlich constant

$M \quad-\quad$ Mass of the adsorbent

$b \quad-\quad$ Adsorption energy (Langmuir constant)

$V \quad-\quad$ Volume of the solute (the dye) solution

$P \% \quad-\quad$ Percentage removal of the dye from the aqueous solution

$\alpha \quad-\quad$ Initial adsorption rate constant

$\beta \quad-\quad$ Parameter related to the extent of the surface coverage and activation energy for the chemisorption

\section{Acknowledgements}

The authors would like to gratefully acknowledge Mrs. REJIMI Aziza (Director of the ceramic Company ETER, Guelma, Algeria) for providing the raw clays DD3 and KT2. 


\section{References}

[1] K. Kadrivelu, M. Kavipriya, C. Karthika, M. Radhika, N. Vennilamani, S. Pattabhi, Utilization of various agricultural wastes for activated carbon preparation and application for the removal of dyes and metal ions from aqueous solutions, Bioresour. Technol., 87 (2003) 129-132.

[2] A.K. Jain, V.K. Gupta A. Bhatnagar, Suhas, Utilisation of industrial waste products as adsorbents for the removal of dyes, J. Hazard. Mater., B101 (2003) 31-42.

[3] I.K. Kapdan, F. Kargi, Simultaneous biodegradation and adsorption of textile dyestuff in an activated sludge unit, Process Biochem., 37 (2002) 973-981.

[4] A. Pala, E. Tokat, Colour removal from cotton textile industry wastewater in an activated sludge system with various additives, Water Res., 36 (2002) 2920-2925.

[5] C. Allegre, P. Moulin, M. Maisseu, F. Charbit, Treatment and reuse of reactive dyeing effluents, J. Membr. Sci., 269 (2006) 15-34.

[6] H. Javadian, M. Torabi Angaji, M. Naushad, Synthesis and characterization of polyaniline/g-alumina nanocomposite: a comparative study for the adsorption of three different anionic dyes, J. Ind. Eng. Chem., 20 (2014) 3890-3900,

[7] A. Pirkarami, M. Ebrahim Olya, F. Najafi, Removal of azo dye from aqueous solution using an anionic polymeric urethane absorbent (APUA), J. Ind. Eng. Chem., 21 (2015) 387-393.

[8] P. Cooper, Removing colour from dyehouse waste waters - a critical review of technology available, J. Soc. Dyers Colour., 109 (1993) 97-100.

[9] T. Clark, M. Bruce, S. Anderson, Decolourisation of extraction stage bleach plant effluent by combined hypochlorite oxidation and anaerobic treatment, Water Sci. Technol., 29 (1994) 421-432.

[10] E.G. Solozhenko, N.M. Soboleva, V.V. Goncharuk, Decolourization of azo dye solutions by Fenton's oxidation, Water Res., 29 (1995) 2206-2210.

[11] H.L. Liu, Y.-R., Chiou, Optimal decolourization efficiency of reactive red 239 by $\mathrm{UV} / \mathrm{ZnO}$ photocatalytic process, J. Chin. Inst. Chem. Eng., 37 (2006) 289-298.

[12] K. Treffry-Goatley, C.A. Buckley, G.R. Groves, Reverse osmosis treatment and reuse of textile dyehouse effluents, Desalination, 47 (1983) 313-320.

[13] C.A. Buckley, Membrane technology for the treatment of dyehouse effluents, Water Sci. Technol., 25 (1992) 203-209.

[14] R. Jiraratananon, A. Sungpet, P. Luangsowan, Performance evaluation of nanofiltration membranes for treatment of effluents containing reactive dye and salt, Desalination, 130 (2000) 177-183.

[15] I. Koyuncu, Reactive dye removal in dye/salt mixtures by nanofiltration membranes containing vinyl sulphone dyes: effects of feed concentration and cross flow velocity, Desalination, 143 (2002) 243-253.

[16] V.K. Gupta, S.K. Srivastava, D. Mohan, Equilibrium uptake, sorption dynamics, process optimization, and column operations for the removal and recovery of Malachite green from wastewater using activated carbon and activated slag, Ind. Eng. Chem. Res., 36 (1997) 2207-2218.

[17] V.K. Gupta, Suhas, I. Ali, V.K. Saini, Removal of Rhodamine B, Fast green, Methylene blue from wastewater using red mud, an aluminum industry waste, Ind. Eng. Chem. Res., 43 (2004) 1740-1747.

[18] V.K. Gupta, I. Ali, V.K. Saini, T. Van Gerven, B. Van der Bruggen, C. Vandecasteele, Removal of dyes from wastewater using bottom ash, Ind. Eng. Chem. Res., 44 (2005) 3655-3664.

[19] V.K. Gupta, A. Mittal, V. Gajbe, J. Mittal, Removal and recovery of the hazardous azo dye Acid Orange 7 through adsorption over waste materials: bottom ash and de-oiled soya, Ind. Eng. Chem. Res., 45 (2006) 1446-1453.

[20] S.P. Dubey, K. Gopal, J.L. Bersillon, Utility of absorbents in the purification of drinking water: a review of characterization, efficiency and safety evaluation of various absorbents, J. Environ. Biol., 30 (2009) 327-332.

[21] V.K. Gupta, N. Suhas, Application of low-cost adsorbents for dye removal - a review, J. Environ. Manage., 90 (2009) 2313-2342.
[22] G. Rodney Harris, D. Wells John, B. Johnson Bruce, Selective adsorption of dyes and other organic molecules to kaolinite and oxide surfaces, Colloids Surf., A, 180 (2001) 131-140.

[23] P. Liu, L. Zhang, Adsorption of dyes from aqueous solutions or suspensions with clay nano-adsorbents, Sep. Purif. Technol., 58 (2007) 32-39.

[24] K.O. Adebowale, I.E. Unuabonah, B.I. Olu-Owolabi, Adsorption of some heavy metal ions on sulfate and phosphate-modified kaolin, Appl. Clay Sci., 29 (2005) 145-148.

[25] S.H. Lin, R.S Juang, Y.H. Wang, Adsorption of acid dye from water onto pristine and acid-activated clays in fixed beds, J. Hazard. Mater., B113 (2004) 195-200.

[26] A. Safa Özcan, A. Özcan, Adsorption of acid dyes from aqueous solutions onto acid-activated bentonite, J. Colloid Interface Sci., 276 (2004) 39-46.

[27] A. Boulmokh, Y. Berredjem, K. Guerfi, A. Gheid, Kaolin from Djebel Debbagh Mine, Guelma, Algeria, Res. J. Appl. Sci., 2 (2007) 435-440.

[28] N. Fardjaoui, F.Z. El Berrichi, F. Ayari, Kaolin-issued zeolite A as efficient adsorbent for bezanyl yellow and nylomine green anionic dyes, Microporous Mesoporous Mater., 243 (2017) 91-101.

[29] B. Rabehi, K. Boumchedda, Y. Ghernouti, Study of calcined halloysite clay as pozzolanic material and its potential use in mortars, Int. J. Phys. Sci., 7 (2012) 5179-5192.

[30] S. Mellouk, S. Cherifi, M. Sassi, K. Marouf-Khelifa, A. Bengueddach, J. Schott, A. Khelifa, Intercalation of halloysite from DjebelDebagh (Algeria) and adsorption of copper ions, Appl. Clay Sci., 44 (2009) 230-236.

[31] B. Benguella, A. Yacouta-Nour, Adsorption of Bezanyl Red and Nylomine Green from aqueous solutions by natural and acidactivated bentonite, Desalination, 235 (2009) 276-292.

[32] R. Petschick, G, Kuhn, F. Gingele, Clay mineral distribution in surface sediments of the South Atlantic: sources, transport, and relation to oceanography, Mar. Geol., 130 (1996) 203-229.

[33] M. Kosmulski, Surface Charging and Points of Zero Charge, Surfactant Science Series, CRC Press, 145 (2009) 1064.

[34] A. Jada, S. Erlenmeyer, Zeta potential of calcium carbonate precipitated in the presence of sodium polyacrylates, J. Colloid Sci. Biotechnol., 1 (2012) 129-136

[35] M.A. Al-Ghouti, M. Khraisheh, S.J. Allen, M.N. Ahmad, The removal of dyes from textile wastewater: a study of the physical characteristics and adsorption mechanisms of diatomaceous earth, J. Environ. Manage., 69 (2003) 229-238.

[36] V.K. Garg, R. Gupta, A.B. Yadav, R. Kumar, Dye removal from aqueous solution by adsorption on treated sawdust, Bioresour. Technol., 89 (2003) 121-124.

[37] Z. Aksu, Biosorption of reactive dyes by dried activated sludge: equilibrium and kinetic modeling, Biochem. Eng. J., 7 (2001) 79-84.

[38] E. Errais, J. Duplay, F. Darragi, I. M'Rabet, A. Aubert, F. Huber, G. Morvan, Efficient anionic dye adsorption on natural untreated clay: kinetic study and thermodynamic parameters, Desalination, 275 (2011) 74-81.

[39] A. Bousher, X. Shen, R.G.J. Edyvean, Removal of coloured organic matter by adsorption onto low-cost waste materials, Water Res., 31 (1997) 2084-2092.

[40] K.R. Ramakrishna, T. Viraraghavan, Use of slag for dye removal, Waste Manage., 17 (1997) 483-488.

[41] R. Klimaviciute, A. Riauka, A. Zemaitaitis, The binding of anionic dyes by cross-linked cationic starches, J. Polym. Res., 14 (2007) 67-73.

[42] F. Renault, N. Morin-Crini, F. Gimbert, P.M. Badot, G. Crini, Cationized starch-based material as a new ion-exchanger adsorbent for the removal of C.I. Acid Blue 25 from aqueous solutions, Bioresour. Technol., 99 (2008) 7573-7586.

[43] S. Rosa, C.M.L. Mauro, H.G. Riela, V.T. Favere, Cross-linked quaternary chitosan as an adsorbent for the removal of the reactive dye from aqueous solutions, J. Hazard. Mater., 155 (2008) 253-260.

[44] M. Constantin, I. Asmarandei, V. Harabagiu, L. Ghimici, P. Ascenzi, Removal of anionic dyes from aqueous solutions by an ion-exchanger based on pullulan microspheres, Carbohydr. Polym., 91 (2013) 74-84. 
[45] M.I. Khalil, A.A. Aly, Use of cationic starch derivatives for the removal of anionic dyes from textile effluents, J. Appl. Polym. Sci., 93 (2004) 227-234.

[46] M. Dogan, M. Alkan, O. Demirbas, Y. Ozdemir, C. Ozmetin, Adsorption kinetics of maxilon blue GRL onto sepiolite from aqueous solutions, Chem. Eng. J., 124 (2006) 89-101.

[47] S. Senthilkumaar, P. Kalaamani, C.V. Subburaam, Liquid phase adsorption of Crystal violet onto activated carbons derived from male flowers of coconut tree, J. Hazard. Mater., 136 (2006) 800-808.

[48] G.C. Catena, F.V. Bright, Thermodynamic study on the effect of cyclodextrin inclusion with anilono naphthalene sulphonates, Anal. Chem., 61 (1989) 905-909.

[49] L.K. Fraji, D.M. Hayer, T.C. Werner, Static and dynamic fluorescence quenching experiments for the physical chemistry laboratory, J. Chem. Educ., 69 (1992) 205-215.

[50] B. Makhoukhi, Modification de la bentonite par divers sels organiques - Application à la décolouration des huiles et à l'adsorption des colourants textiles. Thèse de doctorat, Tlemcen, 2008.

[51] A.W. Adamson, Physical Chemistry of Surfaces, Wiley, New York, 1990

[52] I. Langmuir, The adsorption of gases on plane surfaces of glass, mica and platinum, J. Am. Chem. Soc., 40 (1918) 1361-1403.

[53] H.M.F. Freundlich, Uber die adsorption in losungen, Z. Phys. Chem., 57A (1906) 385-470.
[54] C. Namasivayam, R. JeyaKumar, R.T. Yamuna, Dye removal from wastewater by adsorption on 'waste' $\mathrm{Fe}(\mathrm{III}) / \mathrm{Cr}(\mathrm{III})$ hydroxide, Waste Manage., 14 (1994) 643-648.

[55] S. Lagergren, Zur theorie der sogenannten adsorption geloester stoffe, K. Sven. Vetensk.akad. Handl., 24 (1898) 1-39.

[56] Y.S. Ho, G. McKay, Sorption of dye from aqueous solution by peat, Chem. Eng. J., 70 (1998) 115-124.

[57] Y.S. Ho, G. McKay, Kinetic models for the sorption of dye from aqueous solution by wood, Process Saf. Environ., 76 (1998) 183-191.

[58] W.J. Weber, J. Morris, Kinetics of adsorption on carbon from solution, J. Sanitary Eng. Div., 89 (1963) 31-59.

[59] S.J. Elovich, Proceedings of the Second International Congress on Surface Activity, Vol. 11, in J.H. Schulman, Ed., Academic Press, Inc, New York, 1959, p. 253.

[60] B. Benguelin, A. Yochouta-Nour, Elimination des colourants acides en solution aqueuse par la bentonite et le Kaolin, C. R. Chimie, 12 (2009) 762-771.

[61] Y. Li, B. Gao, T. Wu, B. Wang, X. Li, Adsorption properties of aluminum magnesium mixed hydroxide for the model anionic due reaction brilliant Red K-2BP, J. Hazard. Mater., 164 (2009) 1098-1104.

[62] Q.Y. Yue, Q. Li, Y. Su, B.Y. Gao, J. Li, Two-step kinetic study on the adsorption desorption of reactive dye at cationic polymer/ bentonite, J. Hazard. Mater., 165 (2009) 1170-1178. 